\title{
Active Life: a project for a safe hospital-community transition after arthroplasty
}

\author{
Vida Ativa: projeto para uma transição hospital-comunidade segura após artroplastia
}

Vida Activa: proyecto para una transición hospital-comunidad segura después de una artroplastia

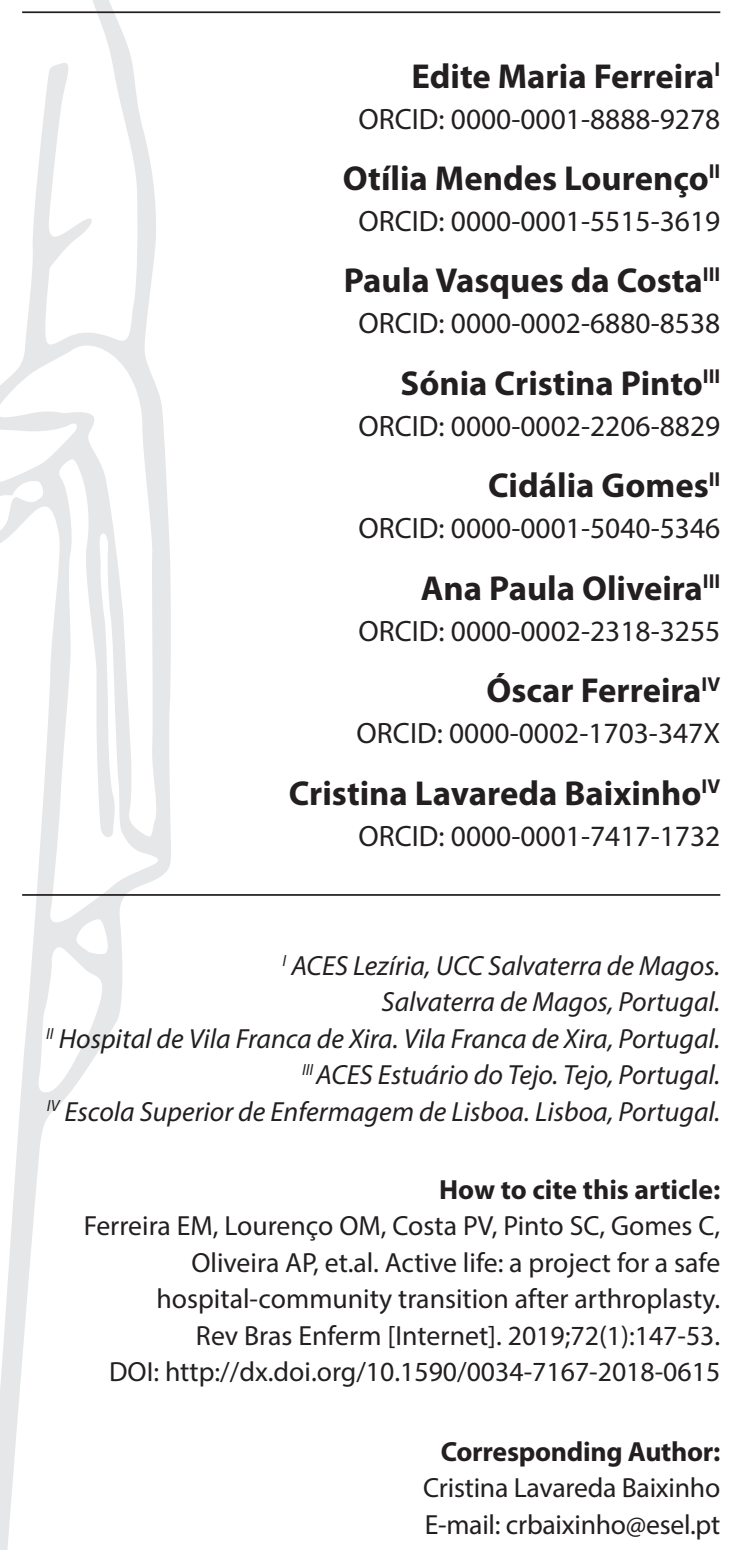

Submission: 07-31-2018

Approval: 08-26-2018

\section{ABSTRACT}

Objective: To define the criteria for the continuity of care to elderly people submitted to arthroplasty. Method: This is a qualitative study, inserted in the constructivist paradigm, whose methodological option fell on research-action. The participants were the health professionals of an orthopedic service and of the community care teams in the area of the hospital. Results: The different techniques allowed us to identify the difficulties in the safe transition from the hospital to the community. At this level, two categories of criteria for continuity of care emerged: criteria associated with the risk of ineffective management of the therapeutic regimen, and criteria associated with the knowledge and level of competence of the informal caregiver. Final Considerations: An elderly person undergoing arthroplasty (hip or knee) has functional alterations that affect their capacity for self-care and may lead to dependence, our findings allowed the design of an algorithm to facilitate clinical decision making and promote a safe hospital-community transition.

Descriptors: Elderly; Arthroplasty; Continuity of Patient Care; Self-Care; Caregivers.

\section{RESUMO}

Objetivo: Definir os critérios para a continuidade da assistência à pacientes idosos submetidos à artroplastia. Método: Estudo qualitativo, inserido no paradigma construtivista, utilizando a pesquisa-ação como opção metodológica. Os participantes do estudo foram os profissionais de saúde de um serviço ortopédico e das equipes de saúde comunitária na área de cobertura do hospital. Resultados: As diferentes técnicas utilizadas nos permitiram identificar as dificuldades para uma transição segura do hospital para a comunidade. Duas categorias de critérios para a continuidade da assistência surgiram: critérios associados ao risco de gestão ineficiente do regime terapêutico, e critérios associados ao conhecimento e nível de competência do cuidador informal. Considerações finais: Um idoso submetido a artroplastia (quadril ou joelho) sofre alterações funcionais que afetam a sua capacidade de autocuidado e podem levar à dependência. Nossos achados permitiram o desenvolvimento de um algoritmo para facilitar a tomada de decisão clínica e promover uma transição segura do hospital para a comunidade.

Descritores: Idoso; Artroplastia; Continuidade da Assistência ao Paciente; Autocuidado; Cuidadores.

\section{RESUMEN}

Objetivo: Definir los criterios para la continuidad de la atención a pacientes ancianos sometidos a la artroplastia. Método: Estudio cualitativo, fundamentado en el paradigma constructivista, utilizando la investigación-acción como opción metodológica. Los participantes del estudio fueron los profesionales de salud de un servicio ortopédico y de los equipos de salud comunitaria en el área de cobertura del hospital. Resultados: Las diferentes técnicas utilizadas permitieron identificar las dificultades para una transición segura del hospital hasta la comunidad. Dos categorías de criterios para la continuidad de la atención surgieron: criterios asociados al riesgo de gestión ineficiente del régimen terapéutico, y criterios asociados al conocimiento y nivel de competencia del cuidador informal. Consideraciones finales: Un anciano sometido a artroplastia (cadera o rodilla) sufre alteraciones funcionales que afectan su capacidad de autocuidado y pueden conducir a la dependencia. Nuestros hallazgos permitieron el desarrollo de un algoritmo para facilitar la toma de decisión clínica y promover una transición segura del hospital hasta la comunidad.

Descriptores: Anciano; Artroplastia; Continuidad de la Atención al Paciente; Autocuidado; Cuidadores. 


\section{INTRODUCTION}

An elderly person undergoing arthroplasty acquires a mobility limitation that will, temporarily or permanently, condition their self-care. At the time of discharge, the person may be in worse functional condition than at the time of admission to the service, which will interfere with the evolution of their functional capacity when they are back home, conditioning independence, autonomy, and quality of life, promoting physical and psychological deterioration and social isolation. Discharge from the hospital is a time of change in the daily lives of patients, because it is usually accompanied by an increase in home care and therapeutics ${ }^{(1)}$.

Research shows that the preparation for the surgical intervention, which starts before admission to the hospital, in a multidisciplinary consultation of preoperative preparation, with explanation of surgery and anesthesia, mobility education, walk training and daily life activities training ${ }^{(2)}$, as well as the education of the family caregiver ${ }^{(3)}$, can contribute to the timely planning of the transition from the hospital to their home, enabling the development of adaptive strategies for the patient and their family.

In this care philosophy, supported by some protocols such as rapid recovery or joint care, discharge planning arises as an emerging care in perioperative healthcare. The area of healthcare in the perioperative period has grown in terms of interest, followed by the growing emphasis on home care, reducing hospitalization time, increasing the number of ambulatory surgical procedures, and controlling hospital infection ${ }^{(3)}$, associated with an increase in length of hospital stay.

It should be noted that, in addition to the aforementioned reasons, the promotion of rehabilitation and functional recovery implies the anticipation of interventions to prevent functional decline and to optimize self-care. Therefore, the transition from the hospital to the community must be carried out safely and with the guarantee that the person and their family will have aid and support for the needs felt upon returning home after hospitalization. However, changes are sometimes not addressed effectively during hospitalization, resulting in fragmentation of post-discharge care ${ }^{(1)}$.

It is acknowledged that nurses have a fundamental role in choosing appropriate interventions that ensure continuity of care between the hospital and the community, in order to minimize side effects and disabilities secondary to surgery and to promote the knowledge and skills of the patient and caregiver to adapt to the new health condition ${ }^{(3-5)}$.

The results of an integrative review revealed five thematic categories with the main activities of the nurses in the transition from hospital care to the community: care planning for discharge; assistance in social rehabilitation; health education; coordination with different services; and post-discharge follow-up ${ }^{(6)}$.

However, the guidelines for the time of clinical discharge are often performed mechanically and hurriedly, without considering individual conditions and needs ${ }^{(6-7)}$, and frequently provided only when leaving the hospital(4).

The complexity of current health problems, the reduction of the average hospitalization time and economic containment require a multidisciplinary and interinstitutional approach. Therefore, coordination between levels of care (hospital and home care) requires a multi- and interdisciplinary intervention ${ }^{(5)}$.
This question is more relevant when people who are undergoing arthroplasty present an increased risk of frailty, imposed by comorbidities or prior dependence on self-care ${ }^{(3)}$. Other studies add that patients are vulnerable to loss of continuity experiences when there are health changes or when moving between care organizations, requiring that the elderly person and their caregiver integrate the guidelines and develop specific skills to maintain the care initiated at the hospital ${ }^{(5)}$. However, this process can be hindered by the difficulty in understanding or executing specific guidelines that result from this health-disease transition ${ }^{(3)}$.

Continuity of care guarantees the improvement of the quality of care provided and constitutes an adequate strategy for a policy to be followed by different health services ${ }^{(5)}$. Adequate discharge planning results in a reduction in length of hospital stay and post-discharge readmissions ${ }^{(2)}$ associated with surgical or immobility-induced complications.

Despite these investigators' guidelines, hospital discharge planning and transition to the community continue to be a central area in health care, where the system and practitioners have manifested difficulties in ensuring the effectiveness of continuity of care. It should be noted that a discharge planning unfit for the patient's needs, lack of preparation for self-care at home and inadequate use of community resources do not promote continuity of care.

The reason for these difficulties lies in issues of difficult response and resolution such as the time required for proper return home planning, the organization of care with the introduction of preoperative consultations ${ }^{(2)}$, difficulties in communication among health professionals, non-evaluation of the intervention effectiveness ${ }^{(3,8)}$, and lack of registration and non-systematization of the used protocols.

The researchers also point out that these obstacles contribute to their invisibility in the practice of the profession ${ }^{(5,8)}$, providing gaps in planning the person's return home after arthroplasty and subsequent safe and informed transition between different contexts of care.

Another conditioning factor could be the preparation and participation of the elderly person and their family in this planning $^{(2)}$. We emphasize that more informed patients will also be the ones with greater participation capacity.

In view of the above, it is crucial to study the process of care from the hospital to the community, ensuring a positive discrimination in the provision of the different health systems to the specific and individual needs of each elderly person and their family, ensuring well-being, enabling the surgery to allow not only joint mobility, but also that the person can continue to develop as a human being, and promoting their health.

Nurses have the responsibility to ensure that patients and their families leave the hospital sufficiently prepared and supported, which is achieved through better coordination and communication among professionals, patients, caregivers and health services ${ }^{(6)}$.

\section{OBJECTIVE}

To define the criteria for the continuity of care to elderly people submitted to arthroplasty, in order to ensure a safe transition from the hospital to the community. 


\section{METHOD}

\section{Ethical aspects}

The different institutions involved in the research gave the authorization for this study through a partnership protocol, creating the conditions for the presence of researchers in the clinical context and for the sharing of the knowledge produced.

The participants gave their free and informed consent to participate. Data anonymity and confidentiality were ensured, and the data were coded without identifying patients and their families.

\section{Type of study}

This action research, inserted in the qualitative and constructivist paradigm, took place from 2014 to 2018. This study is part of a more comprehensive project entitled "Safe transition from hospital to community", which includes interventions to other types of health care clients and the phases of problem identification; planning, processing, and analysis of data, action and evaluation. In this article, we present the results of the first three stages of the research process, related to the Active Life project.

The use of an active and participative research methodology was due to the flexibility of this method, with the involvement of different praxis professionals, with the researchers. The interaction between the different actors of different organizations (academy, hospital and primary health care) promoted the sharing between formal and informal knowledge, between theory and practice $^{(9)}$ empowering the individual qualities and capacities of the participants.

Based on the assumption that the scientific method should be used to promote problem solving, to improve knowledge and to translate it rapidly to the final consumers (health professionals) and to the beneficiaries (health care clients) ${ }^{(10)}$, the methodological option to achieve the objective of the research would have to predict a dynamic process in the data collection process, with the analysis, reflection and action to change the clinical practices promoting the translation of knowledge. In this sense, action research is the method that best enabled the apprehension of the object of study and the translation of knowledge.

\section{Methodological procedures}

Moved by the question "How can we guarantee a safe transition, from the hospital to the community, for people undergoing arthroplasty and their family?", this action research made it possible to search for solutions for this problem of praxis; for professionals and researchers to work collaboratively; to change and develop a theory ${ }^{(9)}$.

The present study is part of a more comprehensive project entitled "Safe transition from hospital to community with the aim to ensure continuity of hospital care for the community, improving communication circuits, clinical decision making and ensuring safety".

Two researchers worked with the nursing team and the social service worker of the orthopedic service and with primary health care nurses.

\section{Data source}

The complexity of the phenomenon under study and the high number of constraints guided us to use different data sources for a better apprehension of reality.

Data collection was done through participant observation, semi-structured interviews, consultation of the clinical processes and the notes made by the professionals of the institutions, and team meetings with the presence of researchers and professionals from both contexts of clinical practice.

Participants in the study were nurses (15), the hospital social service worker (1), and primary care nurses (13) from the hospital's area of coverage.

\section{Data gathering and organization}

Two researchers carried out data collection from the different sources. They analyzed the findings separately and exchanged the analysis with each other, until they reached a consensus. The analysis was discussed with the participants. This option delayed the analysis process, but increased its validity.

A key moment for the appreciation of the object of study was the extended meetings with the whole team, where in addition to information sharing and confrontation with the difficulties, it was possible to unveil solutions for the issues that emerged in the team. According to Silva and collaborators ${ }^{(9)}$, this methodology makes it possible to approximate formal to informal knowledge and establish communication between the two cultural universes: those of the specialists and those of the generalists participating.

The diversity of sources and techniques of analysis allowed the inductive work, enriching the findings with the perspective of the different actors, which in addition to increasing the depth of the analysis, enriched the interpretation of the results based on the literature review.

The interviews were not recorded, and the researchers present in the "field" registered the moments of interaction with the professionals ${ }^{(9)}$. At times, written registration of solutions and answers to questions made by the participants was requested. These documents (logbook and participant registration) were analyzed, initially without concern for categorization, and later were sorted, classified and analyzed to obtain answers to the research question.

\section{Data analysis}

The different findings were submitted to content analysis. This process took place in three phases: 1) pre-analysis; 2) exploration of the material; and 3) treatment of results, inference and interpretation $^{(11)}$.

\section{RESULTS}

The analysis of records, participant observation, and meetings made it possible, at the first stage, to diagnose the situation. The first findings show the impact that defragmentation of continuity of care has on a person's support when returning home and on their functionality after arthroplasty. 
As described in a meeting, by a primary care nurse:

The patient was discharged, left the hospital knowing how to walk with crutches, but when he got home he did not have space between the bed and the wall to be able to get up, and so he stopped getting out of bed with fear of dislocating the prosthesis. (R23)

This situation was only reported three weeks after returning home, with the elderly person already having problems associated with immobility syndrome.

This sharing of clinical cases at meetings made it clear that contexts are different and that a house's physical environment can interfere with self-care and independence. Progressively the models in use in services were exposed, as well as the organizational constraints, and the difficulties in coordination and communication between the two levels of care.

The codification of the content analysis of the participants' discourse allowed us to identify the two categories that justify the need for continuity of care: 1) Criteria for continuity of care associated with the risk of ineffective management of the therapeutic regimen; 2 ) Criteria for continuity of care associated with informal caregiver knowledge and level of competence (Chart 1).

Having discerned the problem, the first step for a change was to plan a safe transition process by determining eligibility criteria for patients and their families to ensure continuity of care.

The analysis of clinical records, interviews with the professionals, and the requested notes allowed us to identify, together with the definition of the criteria for continuity, a set of interventions of appreciation, education, daily life activities training and communication that allow the continuity of care. These data were organized in an algorithm (Figure 1). The methodological option of the algorithm is justified to the extent that it promotes faster learning and internalization, allows the introduction of evidence in clinical practice in a faster and more uniform way and facilitates the definition of the particular strategies to be introduced in the computerized systems of documentation support, in this case nursing documentation ${ }^{(12)}$.

For its construction, the guidelines of the Society for Medical Decision Making were followed, as regards the algorithms construction $^{(12)}$.

Chart 1 - Criteria for the continuity of care to people with arthroplasty and their family, Lisbon, 2018

\begin{tabular}{|l|l|}
\hline \multicolumn{1}{|c|}{ Category } & \multicolumn{1}{c|}{ Subcategory } \\
\hline $\begin{array}{l}\text { Criteria for } \\
\text { continuity of care } \\
\text { associated with the } \\
\text { risk of ineffective } \\
\text { management of the } \\
\text { therapeutic regimen }\end{array}$ & Patient's mobility deficit \\
\cline { 2 - 2 } & High risk of fall \\
\cline { 2 - 2 } & High risk of pressure ulcer \\
\cline { 2 - 2 } & Pain management \\
\cline { 2 - 2 } & Management of the therapeutic regimen \\
\cline { 2 - 2 } $\begin{array}{l}\text { Risk of non-adherence to the rehabilitation } \\
\text { of care associated } \\
\text { with the knowledge } \\
\text { and competence } \\
\text { level of the informal } \\
\text { caregiver }\end{array}$ & $\begin{array}{l}\text { Promoting the awareness of the family } \\
\text { caregiver in the acceptance of their role }\end{array}$ \\
\cline { 2 - 2 } & Diagnosing the needs of the family caregiver \\
\cline { 2 - 2 } & $\begin{array}{l}\text { Outlining strategies that meet the needs } \\
\text { of the family caregiver by promoting the } \\
\text { patient's self-care }\end{array}$ \\
\cline { 2 - 2 } & $\begin{array}{l}\text { Improving the coordination/communication } \\
\text { of the hospital and the community dyad in } \\
\text { the accompaniment of the familiar caregiver, } \\
\text { ensuring a safe transition to the community }\end{array}$ \\
\cline { 2 - 2 } & \begin{tabular}{l} 
Caregiver role commitment \\
\cline { 2 - 2 }
\end{tabular} \\
\hline \begin{tabular}{l} 
Supporting the needs of the family caregiver \\
\hline
\end{tabular} \\
\hline
\end{tabular}

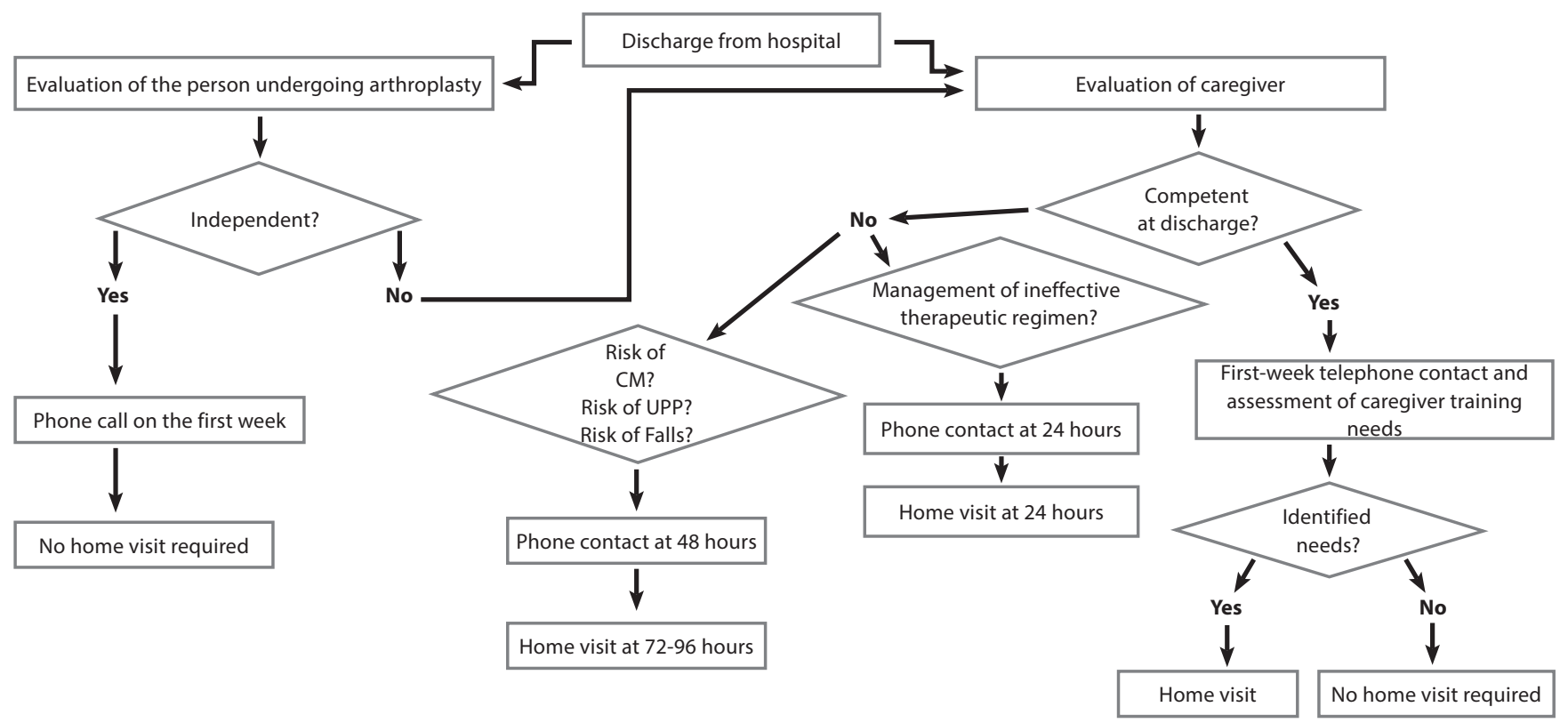

Note: UPP - pressure ulcers, CM - immobility syndrome.

Figure 1 - Algorithm for safe transition from the hospital to the community, of a person with arthroplasty, Lisbon, 2018 
The algorithm designed to ensure a safe transition between hospital and community emphasizes the importance of early discharge planning through a wide range of interventions aimed at the triad care partnership: family caregiver-patient-nurse.

The needs and risks that must be rectified in the hospitalcommunity transition process are expected to be identified during hospitalization.

Independence in daily life activities of the person being treated (dressing and undressing, transfers, walking and use of auxiliary devices, use of the toilet, active mobilization, prevention of falls, pressure ulcers prevention, therapeutic regimen, and pain control) as well as the implementation of strategies (interventions, instruments, and indicators) facilitate the performance of family members, in order to meet the needs identified previously in the hospital.

At the time of discharge, the use of an e-mail with information about the needs of the caregiver was defined as a reference instrument and as indicators of priority intervention in the postdischarge period: patient's mobility deficit; high risk of falls; high risk of pressure ulcer; and as hospital-community interventions to be developed: informing the community resources available (technical aids, social support); and doing a follow-up with the intention of evaluating the training interventions of the familiar caregiver according to their opinion (experienced difficulties and acquired abilities).

\section{DISCUSSION}

The central problem and starting point for this research was the discontinuity of care and the impact it probably has on non-adherence to the therapeutic regimen. The analysis of the different sources allowed to conclude that the activities of the nurses in the transition of care from the hospital to their home are multiple and performed with different complexities, starting during hospitalization and completed when the person is inserted in the home environment ${ }^{(7)}$.

It should be noted that people are vulnerable to experiences of discontinuity of care when their health status changes or when they move between care organizations, and this has implications for their functionality and quality of life.

Fragmentation of continuity of care may result in confusing treatment orientations for the patient, with a strong probability of errors and duplications, inadequate follow-up, as well as a lack of preparation/information for the user and informal care providers $s^{(3,5,7)}$.

Some authors consider that the existence of structured programs with a focus on preoperative preparation through information, education, walk training and daily life activities training directed at both the patient and the caregiver, has a positive impact when returning home, since they are associated with an improvement in functional capacity at discharge and after discharge ${ }^{(2,13)}$.

Anticipating the return home a few weeks before surgery decreases anxiety and fear of surgery, allows the acquisition of supportive products for self-care ${ }^{(2)}$ and the individualization of care, and can provide the opportunity to make changes in the environment. Person-centered care is a health care and nursing process that develops health knowledge and promotes a greater participation of patients who start to manage their health, reinforcing the importance of partnership in decision-making ${ }^{(14)}$.
The preoperative preparation and the organization of care according to the postoperative rehabilitation promote positive and sustainable results, not only in the short term but also in the long term ${ }^{(2,13)}$.

It stands out in the participants' discourse that discharge planning, initiated since admission, provides short- and long-term goal setting, and encourages the involvement of patients and family members in care choices ${ }^{(6)}$ and in social rehabilitation and discharge planning, which presupposes the participation of people in the construction of their care from shared information ${ }^{(7)}$. Participatory discharge planning (family and hospital and primary care staff) provides greater agility in the work of the team, with health gains. On the other hand, the definition of a circuit can strengthen care according to health needs, providing a safe and effective recovery ${ }^{(7)}$.

The structure of a safe transition conditions the professionals' appreciation not only for the reason of hospitalization, but also to identify needs in the continuity of care in the home environment, managing individualized care during hospitalization and promoting post-discharge health ${ }^{(7,15)}$, increasing adherence to treatment and reducing a new hospitalization ${ }^{(15)}$.

It should be noted that the follow-up by the referral primary care nurse includes the possibility of telemonitoring patients with a lower risk of non-adherence, but always complemented by regular check-ups by the multiprofessional team. Teleconsultation, or telephone appointment, or telemonitoring has been assumed as a growing modality in communication in the postoperative nursing care segment ${ }^{(3)}$. The authors reinforce that it has advantages to guarantee and improve access to health care, and provides psychosocial and affective security and bonding in the professional-patient communication ${ }^{(3)}$.

Even when the person is autonomous and independent, postdischarge follow-up is necessary to identify doubts about the treatment prescribed at the hospital and to clarify where to seek care if an unexpected problem arises ${ }^{(16)}$.

Integrative reviews regarding the transition from the hospital to the community have shown that the guidelines provided by nurses are essential to make this transition effective by promoting adherence to medication, managing self-care, increasing adherence to treatment, and reducing rehospitalization, co-morbidity, and mortality ${ }^{(7)}$. This raises the question of whether stimulating and increasing networking among hospital and community care providers, and the use of case managers and/or peer counselors, can also be valuable in facilitating the process. Future studies should try to answer this question.

\section{Study limitations}

The limitations of the study relate to the intentionality of the choice of contexts and participants. The methodology that supported the investigation and the analysis does not allow generalizations for the population, nor for other clinical contexts.

\section{Contributions to the nursing, healthcare, or health policy areas}

Despite its limitations, the study contributes to the discussion about continuity of care, and patient safety in this process and raises questions about the role of nurses as clinical case managers 
and leaders in the management of transitions that people experience throughout the cycle of life and in different contexts.

Some of these findings can be used in training and support research in this area.

\section{FINAL CONSIDERATIONS}

This action research allowed us to reach the objective of the investigation. The dynamic process of data collection, with analysis, reflection, and action to change clinical practices and working together among researchers and clinicians of different levels of care facilitated decision making and response to the problem.

The present study reveals important contributions to the continuity of care between levels of care. In the content analysis of nurses' discourse and records, two broad categories related to the criteria for continuity of care emerge: 1) Criteria for the continuity of care associated with the risk of ineffective management of the therapeutic regime (Patient's mobility deficit; high risk of falls, high risk of pressure ulcer, pain management, management of the therapeutic regimen, risk of non-adherence to the rehabilitation program); 2) Criteria for continuity of care associated with knowledge and competence level of the informal caregiver (Promoting the awareness of the family caregiver in accepting their role; Diagnosing the needs of the family caregiver; Designing strategies that meet the needs of the family caregiver by promoting the self-care of the person; Improving the coordination/communication of the hospital-community dyad in the accompaniment of the family caregiver, ensuring a safe transition to the community, Commitment to the role of caregiver, Supporting the needs of the family caregiver).

It is also important to improve communication networks, to empower the person and their family with knowledge and adaptive strategies to meet the needs and risks of returning home.

The algorithm designed along the action-research process according to the ACP guidelines aims to synthesize the circuit that guarantees a safe hospital-community transition, which was only possible with the definition of criteria for continuity of care associated with the condition clinical empowerment and motivation of the patient, as well as associated with the family caregiver.

In order to obtain an improvement in continuity of care between hospital and community, the content and circuit of information must be defined.

\section{REFERENCES}

1. Meyers AG, Salanitro A, Wallston KA, Cawthon C, Vasilevskis EE, Goggins KM, et al. Determinants of health after hospital discharge: rationale and design of the vanderbilt inpatient cohort study (VICS). BMC Health Serv Res [Internet]. 2014 [cited 2018 Jun 01];14:10. Available from: https://dx.doi.org/10.1186/1472-6963-14-10

2. McDonald S, Page MJ, Beringer K, Wasiak J, Sprowson A. Preoperative education for hip or knee replacement. Cochrane Database Syst Rev [Internet]. 2014 [cited 2018 Nov 02];(5):CD003526. Available from: doi:10.1002/14651858.CD003526.pub3

3. Pereira SK, Santana RF, Morais VSC, Soares TS, Silva DM. Discharge planning in post-operative of elderly: multiple cases study. Rev Fund Care Online [Internet]. 2016 [cited 2018 Jun 02];8(4),4949-55. Available from: https://dx.doi.org/10.9789/2175-5361.2016.v8i4.4949-4955

4. Guerrero KS, Puls SE, Andrew DA. Transition of care and the impact on the environment of care. J Nurs Educ Pract [Internet]. 2014 [cited 2018 Jun 01];4(6):30-6. Available from: https://dx.doi.org/10.5430/jnep.v4n6p30

5. Mendes F, Gemito MLP, Parreirinha C, Cladeira EC, Serra IC, Casas-Novas MV. Continuity of care from the perspective of users. Ciênc Saúde Coletiva [Internet]. 2017 [cited 2018 Jun 01];22(3):843-55. Available from: https://dx.doi.org/10.1590/1413-81232017223.26292015

6. Hesselink G, Flink M, Olsson M, Barach P, Dudzik-Urbaniak E, Orrego C, et al. Are patients discharged with care? A qualitative study of perceptions and experiences of patients, family members and care providers. BMJ Qual Saf [Internet]. 2012 [cited 2018 Jun 02];21(Suppl 1):i39-49. Available from: doi:10.1136/bmjqs-2012-001165

7. Weber LAF, Lima MADS, Acosta AM, Marques GQ. Care transition from hospital to home: integrative review. Cogitare Enferm [Internet]. 2017 [cited 2018 Jun 01];22(3):e47615. Available from: http://docs.bvsalud.org/biblioref/2017/12/876317/47615-209527-1-pb.pdf

8. Ibanez G, Mercedes BPC, Vedana KGG, Miasso Al. [Adherence and difficulties related to drug treatment in patients with depression]. Rev Bras Enferm [Internet]. 2014 [cited 2018 May 22];67(4):556-62. Available from: http://dx.doi.org/10.1590/0034-7167.2014670409 Portuguese.

9. Silva JC, Morais ER, Figueiredo MLF, Tyrrell MAR. [Action research: concepts and applicability in nursing studies]. Rev Bras Enferm [Internet]. 2011 [cited 2018 Jun 02]; 64(3):592-5. Available from: https://dx.doi.org/10.1590/S0034-71672011000300026 Portuguese.

10. Baixinho CL, Ferreira Ó, Marques FM, Presado MH, Cardoso M. Transição segura: um projeto da transferência do conhecimento para a prática clínica. In: Costa AP, Sánches-Gómez MC, Cilleros MV M. A prática na Investigação Qualitativa: exemplos de estudos. Oliveira de Azeméis (PT): Ludomédia, 2017; pp.57-80.

11. Bardin L. Análise de Conteúdo. Lisboa: Edições 70, 2015. 280 p.

12. Proposal for clinical algorithm standards. Society for Medical Decision Making Committee on Standardization of Clinical Algorithms. Med Decis Making. 1992;12(2):149-54.

13. Cooke M, Walker R, Aitken LM, Freeman A, Pavey S, Cantrill R. Pre-operative self-efficacy education vs. usual care for patients undergoing joint replacement surgery: a pilot randomised controlled trial. Scand J Caring Sci [Internet]. 2016 [cited 2018 Jun 14];30(1):74-82. Available from: https://doi.org/10.1111/scs.12223 
14. Kamei T, Takahashi K, Omori J, Arimori N, Hishinuma M, Asahara K, et al. Toward advanced nursing practice along with people-centered care partnership model for sustainable universal health coverage and universal access to health. Rev Lat Am Enfermagem [Internet]. 2017 [cited 2018 Jun 14];25:e2839. Available from: http://dx.doi.org/10.1590/1518-8345.1657.2839

15. Ulin K, Olsson LE, Wolf A, Ekman I. Person-centred care - An approach that improves the discharge process. Eur J Cardiovasc Nurs [Internet]. 2015 [cited 2018 Jun 15];15(3):e19-26. Available from: doi: 10.1177/1474515115569945

16. Keeping-Burke L, Purden M, Frasure-Smith N, Cossette S, McCarthy F, Amsel R. Bridging the transition from hospital to home: effects of the VITAL telehealth program on recovery for CABG surgery patients and their caregivers. Res Nurs Health [Internet]. 2013 [cited 2018 Jun 13];36(6),540-53. Available from: https://doi.org/10.1002/nur.21571 